\title{
Metrics
}

\section{Managing employee surplus: the cats, rats, camels and elephants of strategic downsizing matrix}

\author{
Jatin Pandey
}

Jatin Pandey is Assistant Professor at the

Department of

Organizational Behaviour and Human Resources, Indian Institute of Management Kozhikode, Kozhikode, India.

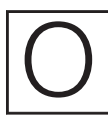

rganizational fat in terms of cost-incurring excess resources that are clogging organizational effectiveness and efficiency are a source of managerial concern. This non-usable fat must be trimmed from an organization with minimum effect on usable muscles (i.e. productive resources). A majority of these resources walk in and out of the organizational elevators everyday. This movement (in terms of hiring, firing and attrition) makes maintaining an optimal number of employees in an organization a significant challenge.

This nonideal situation coupled with dynamics of external and internal business environment lead to cycles of growth in the form of hiring and then decline in the form of firing or downsizing in organizational life. Myopic downsizing in the organization can lead to long-term strategic blindness. Therefore, this operation should be done with caution. This problem can be better understood if organizations are conceptualized as networks.

\section{Organizations as social networks}

A social network comprises a set of actors (nodes) and the relations (ties or edges) amid these actors. With ascending order of complexity in the network, these nodes can be individuals, teams, organizations or society, whereas the edges may represent some level of relationship, i.e. individual-to-individual ties or may cross levels of relationship, i.e. individualto-group ties. This paper conceptualizes nodes as organization's employees and classifies ties as formal, i.e. those dictated by organization and informal, i.e. outside organizational procedures. A representation is given in Figure 1.

From the frame of social network theory, it can be seen that these nodes become asset or resources for organization and their right mix in can lead to a sustained competitive advantage. Downsizing is an extreme measure and requires the dexterity of a surgeon to be performed wisely. In cases where downsizing is necessary, we propose a social network approach to determine which nodes (employees) to be eliminated from the network (organization). From the social network perspective, removal of even one node from the network can result in a potential learning capacity loss that is likely to be far greater than that indicated by simple accounting of head counts. This article, therefore, presents a downsizing model to aid in deciding whom to downsize.

\section{Downsizing model}

This model requires one to compute the cost and benefit of each employee (in case of network it is a node). Each node (employee) has an associated cost that the organization 


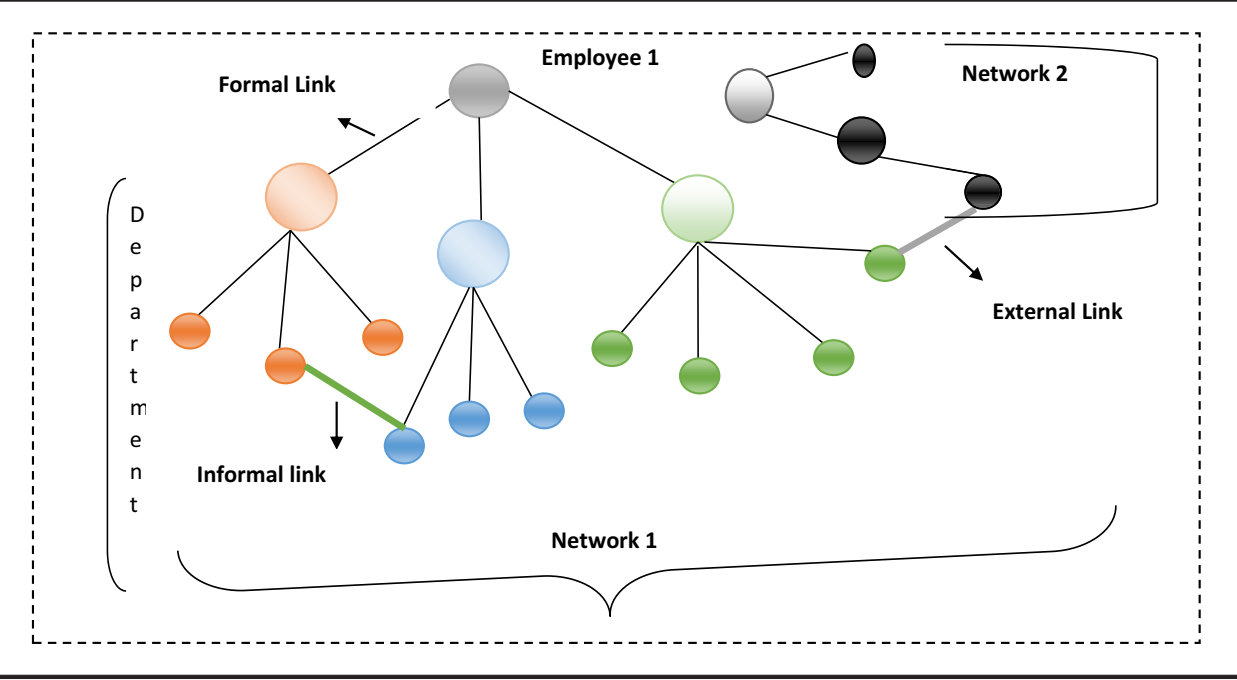

invests on the employee. These costs may range from monetary compensation like salary to non-monetary costs like training and development. The cost of an employee (node in the social network) will thus be a summation of monetary cost (e.g. hiring cost, salary, bonus and development cost) and monetized value of non-monetary benefit (e.g. prestige and power).

Each node (employee) also provides some benefit to an organization that is monetary like the revenue generated or sales achieved and so forth and non-monetary benefits such as leadership skills, organization citizenship behavior, specialized skills and knowledge to name a few. Future usability of the employee should also be taken into account while considering the benefits of an employee. It could be calculated based on the present skill set of individual and skill requirements for foreseeable future projects.

From the social networks approach, the number of ties (formal and informal) the person has with other nodes will get affected if the person is removed is significant. The network value of the node would be the number of people that particular employee can affect internally and externally. Internally the employee can affect her/his fellow employees, bosses and subordinates and externally employee can affect customers and other stakeholders like government, unions and so on.

The centrality measures better capture the network value of a node. The centrality of the node is an attribute which determines the importance of a node within the graph, for example, the importance of an individual in a team. Some common measures of centrality are degree, betweenness and eigenvector centrality.

Degree centrality is defined as the total number of links on a node. It gives a measure of number of nodes an individual node is connected with and is an important indicator of the ties that will be affected if this node or employee is removed. Betweenness centrality measures the occurrence of the individual node between various shortest paths with respect to other nodes in the graph. A node with higher betweenness centrality is more critical for the flow of information and associations between various subgroups and individual nodes. Betweenness dictates how influential is a node in the spread of information in the network.

Eigenvector centrality is an important measure of centrality which distinguishes between scores awarded based on connections to high-value and low-value nodes. In an 
organization, a node with higher eigenvector centrality is more important to strive for an organizational goal, and hence, there is a lesser chance of consideration while downsizing the team. Information centrality is based on the efficient propagation of information over the network. It applies to groups, classes and individuals. All these centrality measures aid in the evaluation of worth of an employee.

Thus, the benefit of an employee is the summation of monetary benefits, future usability and centrality scores. After computing the scores of each node or employee in the organization in our case, we compute the relative score of all employees and decide on a cut-off value. When the previous exercise is completed, it will result in a matrix discussed below.

\section{Matrix of elimination}

Based on the scores computed, we compute the relative costs and benefits of an individual employee and classify them into the four categories mentioned below (Figure 2). We recommend a specialized approach to these four groups instead of generic prescriptive nature of populist HR literature.

Camel is the ship of the desert (a business environment with low resources in our case) and can sustain harsh conditions for a prolonged period with input of minimal resources, and thus, the cost is low, and the benefit is high. In organizations, they are recruited from previous institutions (colleges in case of a new recruit and previous company in case of an employee with experience) that are not very well-known, and hence, their members do not command premium pay packages and perks by virtue of their association. These members are however excellent workers and resource for the organization. Camels thus are those organizational members that take the least cost and return maximum benefit; these must be conserved.

On the other hand, organizations have rats that are destructive for resources and a lot of investment in rodent control is needed to save resources. These individuals have counterproductive work attitudes and engage in deviant workplace behaviors. These in the organizational context lead to waste and poor utilization of scarce resources. In organizational context, rats are those members that cost high but give little benefit; these must be eliminated.

Elephants are very useful and have a lot of strength but to feed them is a herculean task. In an organizational context, we also have elephants that give high benefits but are also

Figure 2 Downsizing matrix

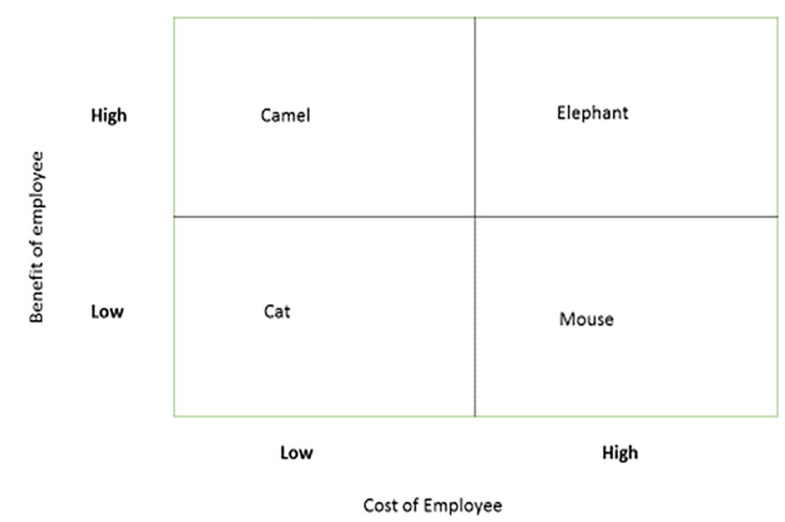

PAGE 222 $\mid$ STRATEGIC HR REVIEW $\mid$ VOL. 17 NO. 42018 
high to maintain. These are members with high qualifications and high performance records and belong to elite heritages in terms of institutions attended. Larger number of elephants would be a strain on an organization, as they are high to maintain, whereas very few would create a deficit of individuals who would represent the face of the organization to the external world.

Cats are easy to maintain and are of very little use in terms of other heavy work that can be extracted from a camel or an elephant. In an organizational context, cats are low-cost, lowvalue employees who must be moved to become camels by assigning them the work of eliminated rats.

Thus, the plan of action would be to remove rats followed by elephant. Business excellence requires few elephants with plenty of camels. The matrix of elimination thus gives directions to managers on how to handle human resources in times of downsizing.

For instructions on how to order reprints of this article, please visit our website: www.emeraldgrouppublishing.com/licensing/reprints.htm

Or contact us for further details: permissions@emeraldinsight.com 